This item was submitted to Loughborough's Research Repository by the author.

Items in Figshare are protected by copyright, with all rights reserved, unless otherwise indicated.

\title{
The barriers, benefits and facilitators of leisure time physical activity among people with spinal cord injury: a meta-synthesis of qualitative findings
}

\section{PLEASE CITE THE PUBLISHED VERSION}

http://dx.doi.org/10.1080/17437199.2014.898406

\section{PUBLISHER}

Routledge (@) Taylor \& Francis)

\section{VERSION}

AM (Accepted Manuscript)

\section{PUBLISHER STATEMENT}

This work is made available according to the conditions of the Creative Commons Attribution-NonCommercialNoDerivatives 4.0 International (CC BY-NC-ND 4.0) licence. Full details of this licence are available at: https://creativecommons.org/licenses/by-nc-nd/4.0/

\section{LICENCE}

CC BY-NC-ND 4.0

\section{REPOSITORY RECORD}

Williams, Toni L., Brett M. Smith, and Anthony Papathomas. 2014. "The Barriers, Benefits and Facilitators of Leisure Time Physical Activity Among People with Spinal Cord Injury: A Meta-synthesis of Qualitative Findings". Loughborough University. https://hdl.handle.net/2134/17173. 
RUNNING HEAD: PHYSICAL ACTIVITY AND SPINAL CORD INJURY

\begin{abstract}
Objectives: Physical activity can have a positive impact upon health and well-being for people with spinal cord injury (SCI). Despite these benefits, people with SCI are within the most physically inactive segment of society that comprises disabled people. This original metasynthesis of qualitative research was undertaken to explore the barriers, benefits and facilitators of leisure time physical activity (LTPA) among people with SCI. Methods: Articles published since 2000 were identified through a rigorous search of electronic databases, supported with a hand search of relevant journals and papers. In total, 64 papers were read in full, and based on inclusion criteria, 18 were relevant for review. The key themes constructed from the data were summarised, compared and synthesised. Results: Eight inter-related concepts were identified as barriers, benefits and/or facilitators of LTPA: 1) well-being; 2) environment; 3) physical body; 4) body-self relationship; 5) physically active identity; 6) knowledge; 7) restitution narrative; 8) perceived absences. Conclusions: Based on the synthesised evidence, healthcare professionals need to appreciate the relationships between the barriers, benefits and facilitators of LTPA in order to successfully promote a physically active lifestyle. Equally, a more critical attitude to physical activity promotion is called for in terms of possible adverse consequences.
\end{abstract}

Key words: Meta-synthesis, spinal cord injury, leisure time physical activity, health, well-being. 


\section{Introduction}

In the UK someone is paralysed by spinal cord injury (SCI) every eight hours. People with SCI are faced with an immediate loss of function and reduced mobility and are at risk of future complications including secondary health conditions (Chen et al., 2011; Hitzig, et al., 2008), poor mental health and increased disability (Krause and Saunders, 2011). Being physically active can not only prevent secondary health conditions among people with SCI, but has the capability to improve overall health, well-being and quality of life (QOL) (Martin Ginis et al., 2012). Despite the benefits of physical activity (PA), people with SCI are within the most inactive segment of society that comprises disabled people (Letts et al., 2011). Therefore health and PA promotion needs to be taken seriously within this population.

Before any improvements to PA promotions can be instigated, the barriers, benefits and facilitators of being physically active for people with SCI need to be understood. As Vissers et al. (2008) highlight: 'To optimize the rehabilitation programme in persons with SCI after discharge with respect to a more physically active lifestyle, it is important to determine the barriers to and facilitators of physical activity after their discharge' (p.461). In other words, by understanding what factors constrain and promote PA in the SCI population, healthcare professionals, governing bodies, rehabilitation centres and community organisations will be in a better position to support disabled people to be physically active for life. One way to rigorously deepen the understanding of barriers, benefits and facilitators of PA for people with SCI is through the systematic review of literature and meta-synthesis of qualitative research on this topic.

A meta-synthesis is 'a rigorous and explicit research method which aims to locate, critically appraise and synthesise the findings of multiple studies pertaining to a specific research question’ (Hammell, 2007, p.125). There are various reasons why a meta-synthesis is needed at this point in time. Firstly, this synthesis of qualitative evidence provides the opportunity to enrich understanding of the quantitative data on PA behaviour and inform evidence-based healthcare practice (Hagger, 2013; Walsh and Downe, 2005). Secondly, qualitative research methods are able to identify relationships to PA that 'emerged from people’s lived experience' of SCI (Fekete and Rauch, 2012, p.148). Thirdly, the psychosocial literature on Paralympic athletes including those with SCI has already been subjected to a systematic review (Jefferies et al., 2012), leaving a significant gap in the literature for a synthesis of data on SCI and participation in leisure time 


\section{RUNNING HEAD: PHYSICAL ACTIVITY AND SPINAL CORD INJURY}

physical activity (LTPA). LTPA is defined as an activity people choose to partake in their spare time such as exercising in the gym, playing recreational sport, or general wheeling (Martin Ginis et al., 2010; Smith, 2013). By focusing on LTPA rather than elite sport, this paper will be applicable to the wider SCI community. It will contribute original and significant knowledge by not only drawing together work on LTPA, but also informing healthcare professionals on LTPA promotion.

\section{Focus of the meta-synthesis}

The purpose of this meta-synthesis was to a) systematically search and appraise the qualitative research on LTPA for people with SCI; b) synthesise knowledge from existing research regarding the barriers, benefits and facilitators to being physically active; and c) based on the results propose improvements to LTPA promotion in SCI for healthcare professionals. The following research question was established: What does the published qualitative literature contribute to our empirical knowledge of the barriers, benefits and facilitators of LTPA after SCI?

\section{Methods}

The process of meta-synthesis of qualitative data consists of five consecutive phases. These are as follows: identifying the focus of the review; identifying published papers relevant to the research question; appraising the studies for research quality; identifying and extracting the relevant data and summarising key themes from each paper; and comparison and synthesis of key themes into new concepts (Hammell, 2007; O’Connell and Downe, 2009; Walsh and Downe, 2005).

\section{Identifying published papers and determining relevance}

The first stage of the meta-synthesis was to identify published papers relevant to the focus of the review on barriers, benefits and facilitators to LTPA in people with SCI. Published articles from January 2000 to December 2012 were identified by searching the following databases: Medline, PsychINFO, PsycARTICLES, Scopus, SPORTSDiscus and World of Knowledge. Articles prior to 2000 were disregarded due to reduced hospitalisation periods for SCI and improved community facilities for wheelchair users over the last decade (Letts et al., 2011; Levins et al., 2004). Therefore studies from 2000 were more relevant to any future LTPA promotions. The search terms used related to SCI, qualitative research and LTPA to identify as many relevant published articles as possible: 
1) Terms for SCI: 'spinal cord injur*' OR paraplegi* OR tetraplegi* OR quadraplegi*.

2) Terms for methodology: 'qualitative research' OR 'focus group*' OR interview* OR ethnograph* OR 'participant observation*' OR interpret* OR 'life world*' OR 'lived experience*' OR 'grounded theory’ OR ‘content analysis’ OR 'discourse analysis’ OR ‘thematic analysis’ OR ‘constant comparative’ OR ‘narrative analysis’ OR ‘conversation analysis’ OR hermeneutic* OR phenomenology.

3) Terms for leisure time physical activity: 'leisure time physical activity' OR 'physical activit*' OR ‘physically active’ OR exercise OR sport* OR fitness OR ‘active living' OR training OR leisure.

The literature search identified 2878 citations from the six databases after the removal of duplicates and non peer-reviewed resources (Figure 1). An additional hand search was conducted of relevant journals and papers to compensate for any insufficient database indexing (Hammell, 2007; Walsh and Downe, 2005). These were identified through reference lists, bibliographies, citation searching and contact with experts.

Based on the research question, primary inclusion criteria for this study were as follows: a) a qualitative research methodology was used, b) the research focused on a SCI population, c) the group sampled in this work were discharged from a spinal unit and living in the community, d) the research contained data on at least one of the factors impacting participation in LTPA (e.g. barriers, benefits, facilitators), e) the empirical data was published in a peer review journal, and f) the full text was in English. Studies were excluded if: a) the sample was not exclusively spinal cord injured, b) the research relied solely on third party evidence (e.g. therapist, carer, partner), c) the participants were under the age of 18 , d) the participants competed in elite sport (i.e. Paralympic or International athletes), e) the studies were outside of the Western world, and f) the primary methodology was quantitative.

In line with a meta-synthesis, the papers were first appraised based on the relevance of the title to the focus of the review. In total 2399 papers were removed because the title was overtly unrelated to the research question. The abstracts of the remaining 479 papers were then read and either accepted or rejected based on the inclusion and exclusion criteria. Through this process 415 papers were removed. Where the abstract suggested potential relevance to the research question, or did not provide enough information to apply the inclusion/exclusion criteria, the full text of the article was read (Hammell, 2007). From the remaining 64 papers read 
in full, another 46 were removed due to the exclusion criteria. The final 18 papers were identified as being relevant to the review question and no further papers were identified through searching the reference lists of these papers (Figure 1).

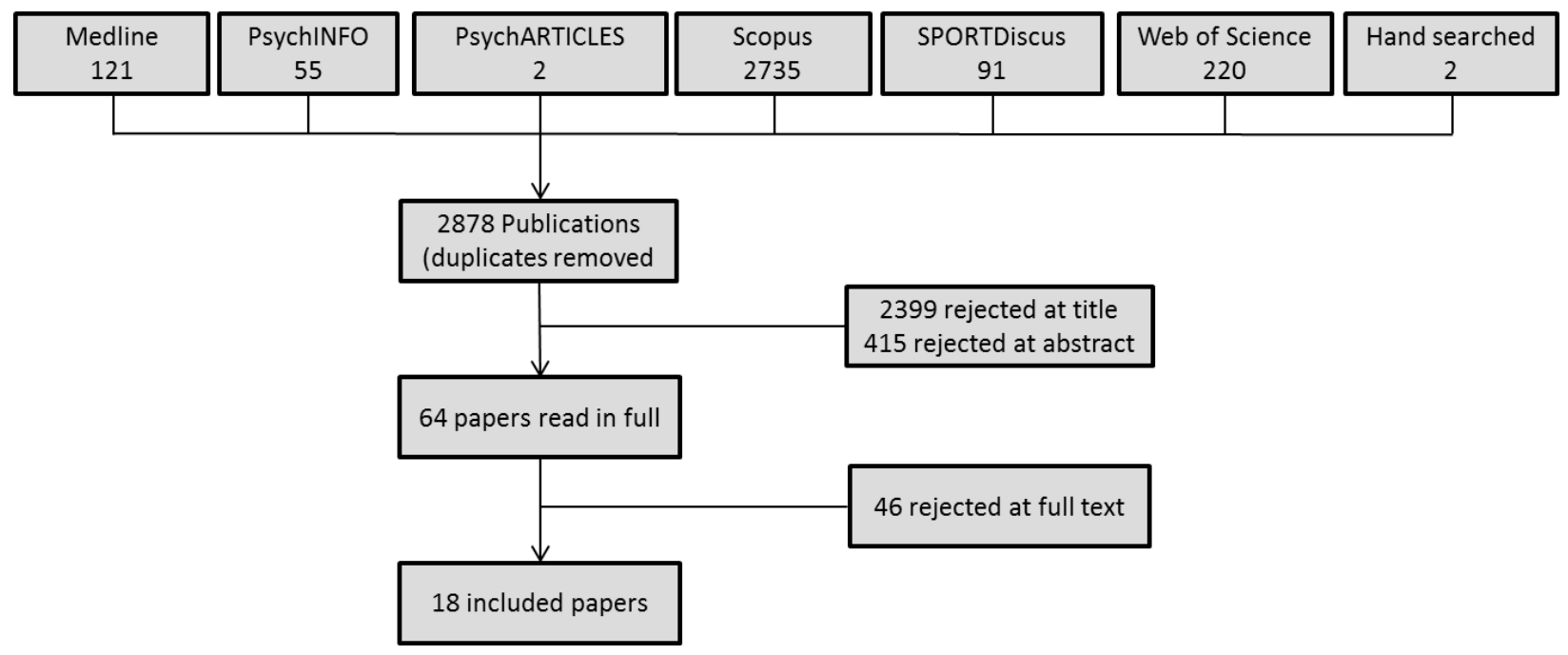

Figure 1: Systematic literature search and exclusion of papers

Although papers had to employ a qualitative methodology, papers were not excluded according to the specific type of qualitative methods used. As expanded upon by Walsh and Downe (2005), 'in the qualitative paradigm, which sees truth as multiple, and knowledge as constructed, it is legitimate to include a variety of approaches in a meta-synthesis' (p.207). This is supported by Sparkes and Smith (2014) who state that qualitative research is an umbrella terms that comprises many multiple traditions and multiple methods. All this said, if papers were of a mixed method design, primarily quantitative with a small section of qualitative research, then they were excluded (Hammell, 2007). The final 18 studies (Table 1) included a wide variety of participants in terms of their age, time since injury and level of injury including both complete and incomplete SCI. Some papers focused on LTPA, whereas other papers explored one aspect of living with SCI that referred to being physically active. These references were brief in places but were included in the meta-synthesis because they added knowledge on the barriers, benefits and facilitators to LTPA for community-dwelling people with SCI.

\section{Quality of the research}

The meta-synthesis involved synthesising research findings from multiple qualitative studies comprising of a variety of research methods. Appraising the quality of these studies has been proposed as a vital stage in the process to avoid including studies with methodological deficiencies (Hammell, 2007; O’Connell and Downe, 2009). There is however no agreed method 


\section{RUNNING HEAD: PHYSICAL ACTIVITY AND SPINAL CORD INJURY}

by which to make this assessment for quality and rigour. The issue of judging quality and rigour within a meta-synthesis is reflective of the larger debate around judging qualitative inquiry in general. 
Table 1: Summary of review papers

\begin{tabular}{|c|c|c|c|c|c|}
\hline Paper & Aim & Sample & Country & Data collection & Design/Analysis \\
\hline $\begin{array}{l}\text { Bowden et } \\
\text { al (2008) }\end{array}$ & $\begin{array}{l}\text { Describe a multidimensional } \\
\text { approach to examine functional } \\
\text { recovery after a therapeutic } \\
\text { intervention }\end{array}$ & $\begin{array}{l}\mathrm{N}=1 \text { (1 man) Age }=59 \\
\text { Injury }=\mathrm{C} \text { level SCI-i } \\
\text { Time since injury }=1.3 \text { years }\end{array}$ & USA & $\begin{array}{l}\text { Semi-structured } \\
\text { interviews }\end{array}$ & $\begin{array}{l}\text { Qualitative } \\
\text { interviewing/thematic } \\
\text { analysis }\end{array}$ \\
\hline $\begin{array}{l}\text { Chun \& } \\
\text { Lee (2010) }\end{array}$ & $\begin{array}{l}\text { Explore the role of leisure in } \\
\text { experience of posttraumatic } \\
\text { growth for people with SCI }\end{array}$ & $\begin{array}{l}\mathrm{N}=15 \text { (10 men) Age range }=27-58 \\
\text { Injury = } \mathrm{C}, \mathrm{T} \text { level } \\
\text { Time since injury }=1-34 \text { years }\end{array}$ & USA & $\begin{array}{l}\text { Open-ended } \\
\text { interviews }\end{array}$ & $\begin{array}{l}\text { Grounded } \\
\text { theory/thematic } \\
\text { analysis }\end{array}$ \\
\hline $\begin{array}{l}\text { Dickson et } \\
\text { al (2011) }\end{array}$ & $\begin{array}{l}\text { Explore lived experiences of } \\
\text { SCI }\end{array}$ & $\begin{array}{l}\mathrm{N}=17 \text { (14 men) Age range }=26-62 \text { years } \\
\text { Injury = C level } \\
\text { Time since injury }=1.4-32 \text { years }\end{array}$ & UK & $\begin{array}{l}\text { Semi-structured } \\
\text { interviews }\end{array}$ & $\begin{array}{l}\text { Interpretive } \\
\text { phenomenological } \\
\text { analysis (IPA) }\end{array}$ \\
\hline $\begin{array}{l}\text { Hannold et } \\
\text { al (2006) }\end{array}$ & $\begin{array}{l}\text { Examine experiences } \\
\text { locomotor training in persons } \\
\text { with incomplete SCI }\end{array}$ & $\begin{array}{l}\mathrm{N}=8 \text { (7 men) Age range }=22-73 \text { years } \\
\text { Injury = C, T level SCI-i } \\
\text { Time since injury }=0.25-3 \text { years }\end{array}$ & USA & $\begin{array}{l}\text { Semi-structured } \\
\text { interviews, } \\
\text { observations of } \\
\text { participants }\end{array}$ & $\begin{array}{l}\text { Grounded } \\
\text { theory/thematic } \\
\text { analysis }\end{array}$ \\
\hline $\begin{array}{l}\text { Kehn \& } \\
\text { Kroll } \\
(2009)\end{array}$ & $\begin{array}{l}\text { Explore barriers and facilitators } \\
\text { of exercise after SCI }\end{array}$ & $\begin{array}{l}\mathrm{N}=26 \text { (16 men) Age range = 23-74 years } \\
\text { Injury = C, } \mathrm{T} \text { level SCI-i/c } \\
\text { Time since injury = 1-32 }\end{array}$ & USA & $\begin{array}{l}\text { Semi-structured } \\
\text { interviews }\end{array}$ & $\begin{array}{l}\text { Ethnographic } \\
\text { approach/content } \\
\text { analysis }\end{array}$ \\
\hline $\begin{array}{l}\text { Letts et al } \\
(2011)\end{array}$ & $\begin{array}{l}\text { Explore preferred methods of } \\
\text { PA communication to people } \\
\text { with SCI }\end{array}$ & $\begin{array}{l}\mathrm{N}=16 \text { (14 men) Age = mean } 52.4 \text { years } \\
\text { Injury = } 6 \text { paraplegic, } 10 \text { tetraplegic } \\
\text { Time since injury = mean } 15.87 \text { years }\end{array}$ & Canada & Focus groups & $\begin{array}{l}\text { Phenomenological } \\
\text { approach/content } \\
\text { analysis }\end{array}$ \\
\hline $\begin{array}{l}\text { Levins et al } \\
(2004)\end{array}$ & $\begin{array}{l}\text { Explore experiences of } \\
\text { individuals with SCI } \\
\text { participating in PA }\end{array}$ & $\begin{array}{l}\mathrm{N}=8 \text { (5 men) Age }=\text { mean } 42 \text { years } \\
\text { Injury = T level SCI-i/c } \\
\text { Time since injury }=2-27 \text { years }\end{array}$ & Canada & $\begin{array}{l}\text { Semi-structured } \\
\text { interviews }\end{array}$ & $\begin{array}{l}\text { Ethnographic } \\
\text { approach/thematic } \\
\text { analysis }\end{array}$ \\
\hline $\begin{array}{l}\text { Lofgren \& } \\
\text { Norrbrink } \\
\text { (2012) }\end{array}$ & $\begin{array}{l}\text { Explore strategies and } \\
\text { treatments used to for pain } \\
\text { management in people with } \\
\text { SCI }\end{array}$ & $\begin{array}{l}\mathrm{N}=18 \text { (11 men) Age range = 28-66 years } \\
\text { Injury = C, } \mathrm{T}, \mathrm{L} \text { level } \\
\text { Time since injury = 3-31 years }\end{array}$ & Sweden & $\begin{array}{l}\text { Diary, } \\
\text { interviews }\end{array}$ & $\begin{array}{l}\text { Grounded } \\
\text { theory/content analysis }\end{array}$ \\
\hline $\begin{array}{l}\text { Manns \& } \\
\text { Chad } \\
(2001)\end{array}$ & $\begin{array}{l}\text { Determine themes that } \\
\text { represent QOL for people with } \\
\text { SCI }\end{array}$ & $\begin{array}{l}\mathrm{N}=15 \text { (9 men) Age range }=22-63 \text { years } \\
\text { Injury = } 8 \text { paraplegic } 7 \text { quadriplegic, SCI-c } \\
\text { Time since injury = mean } 13 \text { years }\end{array}$ & Canada & $\begin{array}{l}\text { Semi-structured } \\
\text { interviews }\end{array}$ & $\begin{array}{l}\text { Ethnographic } \\
\text { approach/thematic } \\
\text { analysis }\end{array}$ \\
\hline $\begin{array}{l}\text { Martin et al } \\
(2002)\end{array}$ & $\begin{array}{l}\text { Explore perceived benefits and } \\
\text { barriers to exercise to better } \\
\text { understand exercise motivation }\end{array}$ & $\begin{array}{l}\mathrm{N}=15 \text { (11 men) Age range }=19-49.5 \\
\text { years } \\
\text { Injury = unknown }\end{array}$ & Canada & $\begin{array}{l}\text { Focus groups, } \\
\text { flip chart notes }\end{array}$ & $\begin{array}{l}\text { Focus group } \\
\text { discussions }\end{array}$ \\
\hline
\end{tabular}




\begin{tabular}{|c|c|c|c|c|c|}
\hline & among people with SCI & Time since injury = unknown & & & \\
\hline $\begin{array}{l}\text { O’Brien et } \\
\text { al (2008) }\end{array}$ & $\begin{array}{l}\text { Explore post injury leisure } \\
\text { participation for individuals } \\
\text { with acquired SCI }\end{array}$ & $\begin{array}{l}\mathrm{N}=18 \text { (unknown) Age range }=31-60 \\
\text { years } \\
\text { Injury = } 7 \text { paraplegic, } 11 \text { tetraplegic } \\
\text { Time since injury = 8-35 years }\end{array}$ & Canada & $\begin{array}{l}\text { Semi-structured } \\
\text { interviews }\end{array}$ & $\begin{array}{l}\text { Modified grounded } \\
\text { theory/thematic } \\
\text { analysis }\end{array}$ \\
\hline $\begin{array}{l}\text { Pentland et } \\
\text { al (2002) }\end{array}$ & $\begin{array}{l}\text { Examine the impact of aging in } \\
\text { women with SCI }\end{array}$ & $\begin{array}{l}\mathrm{N}=29(0 \text { men }) \text { Age range }=35-70 \text { years } \\
\text { Injury = C, } T \text {, L level } \\
\text { Time since injury }=3-38 \text { years }\end{array}$ & Canada & $\begin{array}{l}\text { Focus groups, } \\
\text { interviews }\end{array}$ & $\begin{array}{l}\text { Explanatory models, } \\
\text { thematic analysis }\end{array}$ \\
\hline $\begin{array}{l}\text { Price et al } \\
\text { (2011) }\end{array}$ & $\begin{array}{l}\text { Examine the life satisfaction } \\
\text { and occupational and social } \\
\text { participation of SCI individuals }\end{array}$ & $\begin{array}{l}\mathrm{N}=11 \text { (6 men) Age = unknown } \\
\text { Injury = } 5 \text { paraplegic, } 6 \text { tetraplegic SCI-i/c } \\
\text { Time since injury = 1-5years }\end{array}$ & USA & $\begin{array}{l}\text { Semi-structured } \\
\text { interviews }\end{array}$ & Narrative analysis \\
\hline $\begin{array}{l}\text { Semerjian } \\
\text { et al (2005) }\end{array}$ & $\begin{array}{l}\text { Assess effects of adapted } \\
\text { exercise on QOL and body } \\
\text { satisfaction in people with SCI }\end{array}$ & $\begin{array}{l}\mathrm{N}=12 \text { (8 men) Age range = 18-51 years } \\
\text { Injury = C, T level } \\
\text { Time since injury = 1-30 years }\end{array}$ & USA & $\begin{array}{l}\text { Semi-structured } \\
\text { interviews, field } \\
\text { notes }\end{array}$ & Grounded theory \\
\hline $\begin{array}{l}\text { Smith } \\
(2013)\end{array}$ & $\begin{array}{l}\text { Examine health narratives told } \\
\text { by men with SCI }\end{array}$ & $\begin{array}{l}\mathrm{N}=17 \text { (17 men) Age = unknown } \\
\text { Injury = unknown } \\
\text { Time since injury = unknown }\end{array}$ & UK & $\begin{array}{l}\text { Life history } \\
\text { narrative } \\
\text { interviews, field } \\
\text { work } \\
\text { observations }\end{array}$ & Narrative analysis \\
\hline $\begin{array}{l}\text { van de Ven } \\
\text { et al. } \\
\text { (2008) }\end{array}$ & $\begin{array}{l}\text { Identify strategies used by } \\
\text { people with high cervical SCI } \\
\text { to function autonomously }\end{array}$ & $\begin{array}{l}\mathrm{N}=8 \text { ( } 5 \text { men) Age range }=27-55 \text { years } \\
\text { Injury = C level } \\
\text { Time since injury }=3-32 \text { years }\end{array}$ & $\begin{array}{l}\text { The } \\
\text { Netherlan } \\
\text { ds }\end{array}$ & $\begin{array}{l}\text { Semi-structured } \\
\text { interviews }\end{array}$ & $\begin{array}{l}\text { Qualitative } \\
\text { research/thematic } \\
\text { analysis }\end{array}$ \\
\hline $\begin{array}{l}\text { Wahman et } \\
\text { al (2006) }\end{array}$ & $\begin{array}{l}\text { Identify factors that promote } \\
\text { participation in PA among } \\
\text { people with SCI }\end{array}$ & $\begin{array}{l}\mathrm{N}=16 \text { (12 men) Age range }=21-61 \text { years } \\
\text { Injury = } 8 \text { paraplegic, } 8 \text { quadriplegic } \\
\text { Time since injury }=2-41 \text { years }\end{array}$ & Sweden & $\begin{array}{l}\text { Semi-structured } \\
\text { interviews }\end{array}$ & $\begin{array}{l}\text { Qualitative multiple } \\
\text { case study } \\
\text { design/cross-case } \\
\text { method analysis }\end{array}$ \\
\hline
\end{tabular}




\section{RUNNING HEAD: PHYSICAL ACTIVITY AND SPINAL CORD INJURY}

Using a pre-determined list of criteria to appraise the quality of research studies is potentially problematic if this does not take into account the different philosophical positions and epistemological assumptions underlying different qualitative research methods (Sparkes and Smith, 2009). Sparkes and Smith (2014) proposed that alternative criteria should be used to judge qualitative research whereby judgements are made based upon lists of criteria that are appropriate to the form of inquiry. These criteria are not universal or static in nature, but are lists of characterising traits that can change over time and in different contexts. This does however present a challenge when some authors in the final papers did not make explicit reference to their theoretical framework and form of inquiry (Table 1).

To compensate for differences in methodology, Garside (2014) recommended that papers in qualitative systematic reviews should be appraised based on criteria of trustworthiness (epistemological aspects), theoretical considerations and practical (technical) considerations. Garside suggests that rather than using one checklist, this method allows for 'careful consideration of the study within its own terms' (p.77). As part of an ongoing list of criteria, examples of considerations included:

- Trustworthiness - Are the design and execution appropriate to the research question? Are alternative interpretations, theories, etc. explored? How well supported by the data are any conclusions?

- Theoretical considerations - Does the report connect to a wider body of knowledge or existing theoretical framework? If so, is this appropriate? Does the paper develop explanatory concepts for the findings?

- Practical considerations - Does the study usefully contribute to the policy question? Does this study provide evidence relevant to the policy setting? Does this study usefully contribute to the review?

As Garside advocates, these lists are not prescriptive but are intended to be indicative of research quality. All authors considered the quality of each paper under these three headings and noted the following. Firstly, trustworthiness was assessed using the above criteria and in all cases each paper had a design appropriate to the research question and used data to supported their concluding statements. Secondly, theoretical considerations were difficult to judge in instances whereby the papers (Martin et al., 2002; O’Brien et al., 2008) were exceptionally short in length. We therefore decided that studies should not be rejected based on the word limits imposed by the 


\section{RUNNING HEAD: PHYSICAL ACTIVITY AND SPINAL CORD INJURY}

journal. Thirdly, for practical considerations, we found that ultimately all papers usefully contributed to the review. Using these guidelines no papers were rejected in the appraisal process.

\section{Summarising themes}

The final studies were read and re-read to become familiar with the findings in each study. Following Hammell (2007), the process of extracting data was carried out by compiling a list of barriers, benefits and facilitators to LTPA mentioned within each paper. Barriers referred to the reasons why people did not participate in PA, discontinued PA or their negative experiences with PA. The benefits included the positive responses and any perceived advantages from participation in LTPA. Facilitators were recorded as factors that allowed people to participate in LTPA or the motivational reasons as to why they started and continued participation in LTPA. The difference between a benefit and a facilitator is of importance because 'while perceived health benefits may act as a facilitator of continued exercise, it would seem that only the anticipation of such benefits would facilitate initial engagement’ (Kehn and Kroll, 2009, p.175).

The summarising themes process allowed for factors raised by the participants from their direct quotes and the themes interpreted by the researchers to be identified. The factors did not have to be explicitly conceptualised across all participants in the original research findings to be included. This point is important because issues of minor concern in one study may have strengthened importance if they occurred across all studies (Hammell, 2007). In cases where there were other participants included in the study (caregivers, therapists etc.) only quotes or themes that were from individuals with SCI were included (Hammell, 2007).

\section{Conceptual synthesis}

The final stage of the meta-synthesis was to compare and synthesise the lists of barriers, benefits and facilitators to LTPA from each paper into new concepts. This process involved grouping the individual factors under unifying labels and drawing relationships to compare and identify themes into general categories (Hammell, 2007; Walsh and Downe, 2005). An analysis of the primary data presented in each paper resulted in the identification of similar themes across the review papers that could be synthesised into key concepts. The synthesised concepts that emerged from the original data were not reduced to themes that were only present across all studies. As Walsh and Downe (2005, p.208) explain, this is because synthesising data is 'not to do with distilling out a core meaning or reducing down related categories so that they can be 


\section{RUNNING HEAD: PHYSICAL ACTIVITY AND SPINAL CORD INJURY}

placed under an umbrella of some all-encompassing theory or explanation'. Analysing data in a meta-synthesis should aim to preserve the meaning from the original text. Trying to force a homogenous fit between all studies does not follow the interpretivist epistemology of qualitative research (Weed, 2008). Many of the themes and final concepts identified were not mutually exclusive as a barrier, benefit or facilitator of LTPA. However, for ease of representation, the themes were illustrated as separate entities. This said, the relationships between the themes are explored in the subsequent discussion.

\section{Results}

The results of the meta-synthesis revealed eight overarching concepts that acted as barriers, benefits or facilitators of LTPA participation in people with SCI (Table 2). These were: 1) wellbeing; 2) environmental influences; 3) physical body; 4) body-self relationship; 5) physically active identity; 6) knowledge on LTPA; 7) restitution narrative; and 8) perceived absences.

Table 2: Concepts and themes and the papers in which they were found

\begin{tabular}{|c|c|c|}
\hline Concept & Theme & Papers \\
\hline \multirow[t]{3}{*}{ Well-being } & Subjective well-being & 12357891011121415161718 \\
\hline & Psychological well-being & 257111214151618 \\
\hline & Social well-being & 56710131415161718 \\
\hline \multirow{3}{*}{$\begin{array}{l}\text { Environmental } \\
\text { issues }\end{array}$} & Material & 357910111215161718 \\
\hline & Geographical & 5151618 \\
\hline & Social support & 125671011131415161718 \\
\hline \multirow[t]{4}{*}{ Physical body } & Biological impairment & 45811121617 \\
\hline & Biological improvement & 12589101112141516 \\
\hline & Illness prevention & 5891114151618 \\
\hline & Health maintenance & 59141518 \\
\hline \multirow{4}{*}{$\begin{array}{l}\text { Body-self } \\
\text { relationship }\end{array}$} & Disrupted body-self & 45710 \\
\hline & Reintegrated body-self & 45791013141516 \\
\hline & Disabled Identity & 4714101315161718 \\
\hline & Body-self compassion & 15 \\
\hline \multirow{3}{*}{$\begin{array}{l}\text { Physically active } \\
\text { identity }\end{array}$} & Physically active identity & 27811131416 \\
\hline & Development of active identity & 25713141518 \\
\hline & Continuation of active identity & 2571118 \\
\hline \multirow{3}{*}{$\begin{array}{l}\text { Knowledge of } \\
\text { LTPA }\end{array}$} & Lack of information & 56710121516 \\
\hline & Healthcare professionals & 56710151617 \\
\hline & Gaining information & 671113151618 \\
\hline \multirow{2}{*}{$\begin{array}{l}\text { Restitution } \\
\text { narrative }\end{array}$} & Recovery & 1241410 \\
\hline & Normative activity & 14 \\
\hline \multirow[t]{3}{*}{ Perceived absences } & Lack of motivation & 56789101215 \\
\hline & Lack of time & 56910111216 \\
\hline & Rejection of disability sport & 571516 \\
\hline
\end{tabular}


Lofgren \& Norrbrink (2012); 9 = Manns \& Chad (2001); 10 = Martin et al. (2002); $11=$ O’Brien et al. (2008); 12 = Pentland et al. (2002); 13 = Price et al. (2011); 14 = Semerjian et al. (2005); 15 = Smith (2013); 16 = Stephens et al. (2012); 17 = van de Ven et al. (2008); 18 = Wahman et al. (2006).

\section{Well-being}

The results of the meta-synthesis revealed that an individual's well-being impacted upon their engagement in LTPA. Well-being generally refers to 'optimal psychological function and experience' (Ryan and Deci, 2001, p.142). There are two distinct perspectives of well-being that originate from difference philosophical traditions. The first of these is subjective well-being (SWB) which is founded from the hedonic perspective that well-being consists of life satisfaction and happiness (Keyes et al., 2002). The second view is psychological well-being (PWB) from the eudaimonic perspective which relates well-being to psychological growth and development (Keyes et al., 2002; Ryan and Deci, 2001).

A person's SWB involves their perceived happiness and satisfaction with life (Keyes et al., 2002; Ryan and Deci, 2001). The research indicated lower levels of SWB as a barrier to being physically active. These included: depression, lack of self-confidence, embarrassment and too much emotional pressure to deal with PA (Levins et al., 2004; Martin et al., 2002; Semerjian et al., 2005; Stephens et al, 2012). On the other hand, participating in LTPA heightened SWB: 'It helped the more complicated emotional adjustment, and ...so that was a tremendous vehicle to build self-esteem, self-confidence and feel capable as a person' (Levins et al., 2004, p.502). Physical improvements in mobility and capability also positively influenced SWB (Bowden et al., 2008; Martin et al., 2002). Improvements in SWB acted to motivate people with SCI to continue being physically active. Indicators of enhanced SWB that facilitated LTPA were experiences of general positive emotions that led to an increase in life satisfaction (O'Brien et al., 2008; Semerjian et al., 2005; Smith, 2013). A strong facilitator of engagement in LTPA amongst the participants in the studies synthesised was the ability to improve and maintain independence: 'The driving force when it comes to the bottom line, is being as independent as possible and not having to ask for help' (Wahman et al., 2006, p.485).

Participation in LTPA also enhanced PWB as indicated through psychological growth and development. PWB is concerned with dimensions of human flourishing and the 'actualisation of human potential' (Ryan and Deci, 2001, p.143). Signs of improved PWB included the following: an improved outlook in life (Semerjian et al., 2005), experiencing posttraumatic growth (Chun and Lee, 2010) and finding a purpose in life (Stephens et al., 2012). 


\section{RUNNING HEAD: PHYSICAL ACTIVITY AND SPINAL CORD INJURY}

Whilst the two constructs of well-being are distinct, there are overlapping and related components (Keyes et al., 2002). The results of the meta-synthesis suggest that SWB and PWB do influence each other. For example, feelings of positive emotion occurred from having a purpose in life as illustrated in the data: 'That's huge for me. It's meant I've been able to work in a demanding job and get my self-worth back as a man’ (Smith, 2013, p.115). Social well-being (social WB) is a sub component of PWB that indicates perceived flourishing and function in an individual's social life (Keyes, 1998). Social WB was additionally enriched through LTPA with indicators of improved social participation and integration (Price et al., 2011; Stephens et al., 2012; van de Ven et al., 2008).

As well as lowered SWB, participants indicated a reduction in social WB as a barrier to participation in LTPA. Feelings of social exclusion stemmed from fear: 'Fear of being out there in public. I kind of shut myself off to the world' (Stephens et al, 2012, p.2067). Participants revealed how, based on their impairments alone, they perceived negative attitudes from the general public (Levins et al., 2004; van de Ven et al., 2008). In contrast, flourishing in both personal and social life experiences through being physically active, facilitated future LTPA participation (Semerjian et al., 2005). Making a valued contribution to society was another motivational factor to participate in LTPA. One example of this was becoming a role model for others with SCI (Wahman et al., 2006). Being dependable, not only as a teammate, but as a family member (Wahman et al., 2006) also facilitated LTPA: 'That's why I go to the gym, to do this with my son, to be a proper dad' (Smith, 2013, p.115).

\section{Environmental influences}

The material, geographical and social environment of individuals with SCI substantially impacted upon their engagement in LTPA. Drawing upon the social relational model of disability (Smith and Perrier, in press), common themes amongst the final studies in the meta-synthesis were the aspects of the material environment that acted as a barrier to participation in LTPA. These included a lack of both personal and communal resources, inadequate finances and the high cost of participating in wheelchair sport (Kehn and Kroll, 2009; Manns and Chad, 2001; Pentland et al., 2002; Smith, 2013; Stephens et al., 2012; Wahman et al., 2006). Even when there were communal exercise facilities, participants came across obstacles such as accessibility and availability (Kehn and Kroll, 2009; Levins et al., 2004; Smith, 2013; Wahman et al., 2006). A lack of facilities in some instances resulted in feelings of frustration at the inability to maintain 


\section{RUNNING HEAD: PHYSICAL ACTIVITY AND SPINAL CORD INJURY}

fitness levels gained in hospital. As one participant expressed: 'Obviously not having the facilities to train your fitness levels drop and you can't do exercises (...) so the exercise sheet you've got is a total waste of space' (Dickson et al., 2011, p.468). On the other hand increased access and availability of facilities, or adequate funding, facilitated participation in LTPA: 'To finally have the chance to work out with equipment that's designed for us and in a place that's laid out in such a way that I can move around and do what I want to do is awesome' (Martin et al., 2002, p.40).

Aspects of the geographical environment that impacted upon LPTA included the weather and transport. Cold wet weather coupled with long distances to facilities, limited transport and parking, all prevented people from being physically active (Kehn and Kroll, 2009; Smith, 2013; Stephens et al., 2012; Wahman et al., 2006). Whereas in the summer months the dry warm weather facilitated LPTA participation.

A perceived lack of social support was another environmental barrier that prevented people with SCI from being physically active. This is a separate theme from social well-being, as in this context we are referring to a person's social environment which includes other people as a physical resource to be physically active. Social support in this instance includes emotional support, advice and guidance, and more tangible support such as physical assistance and providing transport (Cohen et al., 2000). The results of the meta-synthesis highlighted that a lack of personal assistance resulted in being dependent upon others to exercise (Kehn and Kroll, 2009; Levins et al., 2004; Stephens et al., 2012). Social support was therefore crucial in facilitating LTPA. These support networks included: friends, family, peers, disability groups and activity centres (Levins et al., 2004; Martin et al., 2002; Price et al., 2011; Smith, 2013). Moreover, participating in LTPA with peers provided a sense of realisation about what could be achieved with SCI: 'Seeing other people basically other people with the same level injury you have, see what they can do and you just sit there and you go wow - if he can do that, maybe I can too' (Letts et al., 2011, p.133). Additionally, engaging in LTPA provided the opportunity for incidental learning to occur from people with similar injuries and impairments (Chun and Lee, 2010; Stephens et al., 2012). The importance of this benefit from LTPA was reflected in the data: 'At the end of the quad rugby session we always hang around for a while at the bar. And that is the time for me to ask questions and get answers from the others...And those guys together know more than any rehabilitation doctor will ever know’ (van de Ven et al., 2008, p.253). 


\section{Physical body}

SCI has a significant impact on the physical body. Biological impairments including loss of bodily control, fatigue and secondary health conditions all contributed to a lack of LTPA (Hannold et al., 2006; Pentland et al., 2002; Stephens et al., 2012; van de Ven et al, 2008). These reflect the lived experiences of an impaired body from the social relational model of disability (Smith and Perrier, in press). Participation in LTPA was a barrier in itself, as for some people with SCI this resulted in further injury and pain (Löfgren and Norrbrink 2012; O’Brien et al., 2008). Importantly, many of the biological impairments that deterred people from being physically active were improved through regular LTPA. These physical health benefits included increased strength, mobility, fitness and balance (Bowden et al, 2008; Kehn and Kroll, 2009, Martin et al., 2002; Stephens et al., 2012), reducing the effort required for activities of daily living (ADL) and secondary medical conditions (Kehn and Kroll, 2009; Semerjian et al., 2005). Moreover, a significant health benefit from participation in LTPA was that an alternative pain management technique to drug therapy was provided (Bowden et al., 2008; Kehn and Kroll, 2009; Löfgren and Norrbrink, 2012). Different forms of LTPA were reported to control and decrease pain levels: 'When I exercise, I don’t get so many spasms and it (pain) changes from a stinging to a tingling' (Stephens et al, 2012, p.2066).

These health benefits furthermore acted to facilitate LTPA with the aim to maintain health and prevent further illness. Taking responsibility for personal health after SCI contributed towards being physically active: 'since leaving rehab I've felt I oughta take care of my health, physical and mental health’ (Smith, 2013, p.115). Fear of health deterioration from weight gain and secondary health conditions additionally facilitated people with SCI to remain physically active (Manns and Chad, 2001). This was evident in the data: 'I still do it (exercise). Partially out of fear. I don’t want to get any worse...' (Kehn and Kroll, 2009, p.173).

\section{Body-self relationship}

A disruption to people's body-self relationship prevented them from being physically active, especially immediately post injury (Stephens et al., 2012). The loss of an able-bodied identity was coupled with a struggle to accept a new body and identity: 'I don't think anybody really starts to get used to life in a wheelchair within the first couple of years... most people tend to take a few years to really get comfortable with what's happened and kind of come to terms with it' (Levins et al., 2004, p.501). This uncertainty regarding the body was reflected through both 
frustration and disappointment with current abilities, and a fear of PA causing more bodily damage (Hannold et al., 2006; Kehn and Kroll, 2009; Martin et al., 2002).

A benefit of being physically active was that it provided the opportunity to re-establish and re-integrate the body-self relationship (Levins et al., 2004). A sense of body-self compassion was developed through LTPA participation: 'I like exercising as I feel I'm looking after my body, I'm being kind to it now, not hating it like I did straight after the accident, which is part of

adjusting to the injury’ (Smith, 2013, p.114). Furthermore another benefit of being physically active was that people with SCI were able to redefine their identity (Martin et al., 2002; Stephens et al, 2012). This integration of the body-self relationship facilitated continued exercise behaviour as stereotypical disabled identities were challenged: 'I thought people in wheelchairs with a disability were really disabled people. And I had to redefine that in my head... It was a steep learning curve’ (Levins et al., 2004, p.501). Interestingly, participating in sport was a medium that enabled the wheelchair to become a component of a sense of self: 'But, when you're playing rugby you're working with the wheelchair so intensively, it feels like the wheels become your legs, and you overcome your fears' (van de Ven et al., 2008, p.254).

\section{Physically active identity}

Developing and embodying a physically active identity, either through sport or exercise, was both a benefit and a facilitator of LTPA. Sport, competition and athletic performance became central to some participants' lives (Chun and Lee, 2010; Stephens et al, 2012). This physically active identity was also a reason to continue with LTPA participation and became a facilitator. For some participants remaining physically active after SCI was important as they were heavily involved in sport and exercise before their injury (Levins et al., 2004; O’Brien et al., 2008). These individuals were continuing with an identity they had previously embodied: 'Well it (the injury) changed how I exercised... It didn't change the fact that I knew I had to keep my body fit and as young as I could’ (Kehn and Kroll, 2009, p.172). New physically active identities were developed as a result of the perceived benefits of LTPA participation: 'Before I got my injury I was very uninterested in sport... Already, when I was still in the hospital I decided and realised it was up to me (to be physically active), but then it was more of a fight for a worthwhile life' (Wahman et al., 2006, p.486).

\section{Knowledge on LTPA}




\section{RUNNING HEAD: PHYSICAL ACTIVITY AND SPINAL CORD INJURY}

The meta-synthesis revealed that not having knowledge on how and where to exercise was a barrier to being physically active in the community. The participants expressed that information on LTPA specifically for people with SCI was difficult to find (Kehn and Kroll, 2009; Letts et al., 2011; Levins et al., 2004; Martin et al., 2002; Pentland et al., 2002). Additionally, research reported there was a dearth of information available regarding LTPA from healthcare professionals. Some participants commented on how rehabilitation therapists and doctors focused on ADL and did not actively encourage LTPA (Letts et al., 2011; Levins et al., 2004; van de Ven et al, 2008). There was evidence that healthcare professionals were unaware of suitable LTPA opportunities specifically for SCI, as one participant was told: 'well...umm... I don’t know where to send you. Have you looked online?' (Kehn and Kroll, 2009, p.174).

Acquiring the knowledge on where and how to be physically active facilitated LTPA participation for people with SCI. Information was gained through exposure to activities, media resources and interaction with peers (Levins et al., 2004; O’Brien et al., 2008; Price et al., 2011; Smith, 2013; Stephens et al., 2012; Wahman et al., 2006). Some medical professionals were able to facilitate LTPA by distributing information about relevant activities from other patients with SCI: 'They listen to our stories, our crazy stuff and all this...so that's how they pass (it on)' (Letts et al., 2011, p.132).

\section{Restitution narrative}

The restitution narrative is a common storyline that projects the hope for recovery or cure after illness or disability (Frank, 2013). In SCI, the restitution narrative follows the plot of 'Yesterday I was able-bodied, today I'm disabled, but tomorrow I'll be able-bodied again' (Smith and Sparkes, 2005, p.1096). The studies in the meta-synthesis that involved locomotor training, or other exercises with elements of standing and walking suggested restitution in action. Restitution was perceived as a benefit of LTPA as exercise machines that mimicked walking evoked strong emotions about the former self: 'That was an amazing feeling. It gave you some dignity back' (Semerjian et al., 2005, p.102). In this case standing and walking were representative of both normative and desirable activities associated with a 'momentary return' to one's former body.

Restitution as a facilitator was concerned with engaging in LTPA in the hope of recovery. Symptoms from exercise such as discomfort, soreness, spasms and muscle cramps were seen as signs of nerve regeneration and recovery from SCI (Chun and Lee, 2010; Hannold, et al., 2006; Semerjian et al., 2005). Another aim of keeping physically active was to be prepared for 


\section{RUNNING HEAD: PHYSICAL ACTIVITY AND SPINAL CORD INJURY}

treatment in case of a cure: 'One of the reasons why I try to keep my body in shape is because the thought that if in my lifetime there is a cure, I wanna be first in line. And I feel like if I have maintained my health then I would be a good candidate for that' (Semerjian et al., 2005, p.102).

\section{Perceived absences}

There were a collection of perceived absences that acted as a barrier to being physically active including a lack of time, and energy and motivation. For example, following SCI, the time needed for ADL increased. Subsequently, less time was available to engage in LTPA (Letts et al., 2011; Martin et al., 2002; Stephens et al., 2012). A lack of time coupled with a lack of energy left people without the motivation to exercise: 'It's always a challenge to find enough time... the energy that work takes and with the energy that... just meeting your basic needs... there's hardly any time left just to exercise’ (O’Brien et al., 2008). For some participants exercise was simply not an important consideration in life (Kehn and Kroll, 2009). The perceived limited return, compared to the physical investment required to exercise, also contributed to a lack of PA (Löfgren and Norrbrink, 2012). This impacted upon motivation as shown in the data: 'It just takes too much time and too much effort and I don't think the benefits out weigh the costs' (Kehn and Kroll, 2009, p.172).

The findings of the meta-synthesis revealed that there was a lack of motivation and interest from some participants to engage in disability sport in particular. There were various reasons for this. Some participants expressed disappointment in the wheelchair versions of ablebodied sports: 'I tried to play tennis in a wheelchair and I hated it. It wasn't the same game' (Kehn and Kroll, 2009, p.172). Additionally disability sport was not seen as inclusive for ablebodied friends (Stephens et al., 2012). Lastly some women found it difficult to participate with men as they were in the minority (Levins et al., 2004), and some men rejected disability sport as they associated it with unhealthy masculine behaviour (Smith, 2013).

\section{Discussion}

The purpose of the meta-synthesis was to gather existing knowledge on the barriers, benefits and facilitators of LTPA among people with SCI. This is the first synthesis of qualitative research on LTPA and SCI and contributes original and significant knowledge by revealing a deeper understanding of the complexities within the factors that impact LTPA participation. Additionally this meta-synthesis helps to bridge the gap between academic research and practice by proposing improvements to LTPA promotion for healthcare professionals (Backus et al., 


\section{RUNNING HEAD: PHYSICAL ACTIVITY AND SPINAL CORD INJURY}

2013). In order to successfully promote a physically active lifestyle, healthcare professionals need to consider the following points.

Firstly, the relationships between the barriers, benefits and facilitators of LTPA need to be identified. An important finding from the results was that many of the barriers to LTPA were actually reduced as a result of being engaged in regular sport and exercise. Furthermore, the benefits from LTPA participation provided the motivation to continue to be physically active. Improvements of the physical body in the reviewed studies facilitated future LTPA engagement as individuals strived to maintain their health and prevent further illness. Maintaining independence and avoiding secondary health conditions was of paramount importance. This result was in contrast to Williams (2000) who proposed that further functional loss and secondary health conditions may be experienced as 'normal' rather than disruptive to people with chronic illness and impairment. The synthesised results however supported more recent explorations into illness narratives. Larsson and Grassman (2012) proposed that the risk of further physical deterioration may be just as critical and disruptive even years after living with a chronic condition. Participants exercised to avoid future bodily and functional loss as it was anticipated to lead to undesirable outcomes such as a loss of independence and subsequent decreases in both SWB and PWB.

Secondly, healthcare professionals need to recognise that a disabling injury such as SCI can result in a parallel disruption of a person's body-self relationship. A disruption to the sense of self due to the onset of illness and injury has been conceptualised as biographical disruption and is associated with pain, suffering and feelings of depression (Bury, 1982). Disruptions to the sense of self characterised by an uncertainty of current physical abilities, frustrations with performance and a loss of identity since acquiring an SCI, acted as barriers to being physically active. Sport and exercise was beneficial, as highlighted in the meta-synthesis, as a vehicle with which people were able to re-integrate their body-self relationship and re-define their identity. For others however SCI did not necessarily result in disruption. Individuals who were able to continue with a previously embodied physically active identity prior to SCI experienced biographical continuity of this identity (Williams, 2000).

Thirdly, healthcare professionals need to identify credible messengers to effectively communicate the benefits of LTPA, combined with information on where and how to exercise. As with other physical disabilities (Cowan et al., 2013; Martin Ginis et al., 2012; Mulligan et al., 


\section{RUNNING HEAD: PHYSICAL ACTIVITY AND SPINAL CORD INJURY}

2012; Saebu, 2010), the meta-synthesis revealed a lack of knowledge about where and how to exercise as a significant barrier to LTPA. When healthcare professionals were not unable to provide this information, people with SCI turned to their peers for advice and guidance on LTPA. Disability groups and activity centres provided social support that facilitated inspiration, encouragement to be physically active and incidental learning about life with SCI. As Mazanderani et al. (2013) explain, the stories told by people with real life experiences are of value because they contain an 'embodied source of knowledge' (p.897). In other words, people are more likely to value the advice given to them from peers because this knowledge comes from the lived experience of SCI of having and being an impaired body. Additionally, this information is sometimes of greater value than 'disembodied medical knowledge' (Mazanderani et al., 2013, p.896). Due to the difficulties of disseminating LTPA guidelines for people with SCI, providing opportunities for peers as credible messengers to share stories may be one way to more effectively promote healthcare messages (Gainforth et al., 2013).

Although it is undisputed that LTPA provides multiple benefits for people with SCI, a more critical approach to LTPA promotion must be taken. Healthcare professionals need a critical awareness of the possible negative outcomes of promoting sport and exercise for health and well-being. One concern is that by promoting 'exercise as medicine' this in turn promotes a neoliberal health role (Smith and Perrier, in press). Smith and Perrier comment that the health role in this context calls on the individual to be a responsible citizen who must personally take care of his or her own health by doing things like exercising regularly. This attitude negates any social responsibility and leaves the individual accountable for being physically active. This can however be problematic for disabled individuals. As the meta-synthesis demonstrates, people with SCI were taking an active role to responsibly take care of their body and health. However, despite developing a sense of body-compassion and wanting to be physically active, there were still multiple environmental barriers that prevented people from participating in LTPA. The neoliberal health role therefore risks ignoring societal aspects of being able to participate in LTPA and consequently overlooks disablism and social oppression (Smith and Perrier, in press). When an individual is motivated to exercise, but cannot because they are unable to access any LTPA opportunities, this could negatively impact upon their health and well-being.

Additionally, a preoccupation with sport and exercise may inhibit psychological growth and well-being in other ways. For example, Kleiber and Hutchinson caution that 'vigorous 


\section{RUNNING HEAD: PHYSICAL ACTIVITY AND SPINAL CORD INJURY}

physical activity (and particularly sport) is at best a temporary palliative to 'the crisis' of physical disability for spinal injured men and at worst an impediment to a more complete personal transformation following the injury experience' (pp.135-136). The authors suggest that the desire for men to be physically active is brought about by cultural ideals which value a hyper-masculine hero narrative following illness and injury. Participating in sport may therefore perpetuate the ideology that men are valuable solely for their strong and able bodies rather than providing any alternative narratives. This may prevent men with SCI from expressing masculinity in ways outside of physical power and strength and value other dimensions of the self.

Furthermore, there may be dangers to LTPA participation that healthcare professionals need to be aware of. The findings highlighted that some people were acting out the restitution narrative by exercising to prepare them for recovery from their SCI. LTPA accounts that resonate with recovery and the restitution narrative can be problematic. The restitution narrative can have dangerous consequences on well-being when the hope of recovery is not fulfilled (Smith and Sparkes, 2005). When recovery is not forthcoming and there is no other story to turn to (see Frank, 2013), motivation for LTPA may reduce or even cease. For Frank (2013), stories of hope for a specific medical outcome, including the restoration of physical function, or regaining previous health, can limit 'people's ability to find possibilities in a range of potential outcomes' (p.205). As Nunnerley et al. (2013) warn, the hope for recovery can support engagement in rehabilitation but inhibit other aspects of community integration and psychological growth. In other words being physically active for the purpose of recovery could impact upon PWB in the future. These issues cannot be ignored by healthcare professionals. Therefore future research into LTPA participation for people with SCI needs to address the impact of and on well-being over time.

\section{Reflections}

This research not only contributes to original knowledge, but opens the method of meta-synthesis up for future methodological direction. The five stages outlined by Hammell (2007) and Walsh and Downe (2005) appeared at the outset to be straightforward and in essence easy to follow. There were however some limitations that arose due to the methodology of the meta-synthesis which may have importance in future work. Firstly, studies that included other disabilities outside of SCI were excluded because the results did not always identify the participants' quotes 


\section{RUNNING HEAD: PHYSICAL ACTIVITY AND SPINAL CORD INJURY}

with their disability. Secondly, some original data points were not included in the data extraction process because the authors did not explicitly relate participant quotes to LTPA. Therefore there could be other benefits, barriers and facilitators to LTPA that remain to be addressed, but which could not be definitely identified. Whilst this meta-synthesis does not claim to have identified all of the barriers, benefits and facilitators to exercise, it has recognised the relationship between these factors and LTPA promotion. Therefore researchers need to be clearer when presenting their research findings to avoid this issue in future.

Thirdly, as discussed earlier, difficulties arose when judging the quality of the research papers because some did not explicitly identify their conceptual/theoretical framework and form of inquiry. As Garside (2014) notes, qualitative papers frequently focus on the research findings at the expense of detailing their methodology. Overall she concludes there is a lack of consensus in the qualitative community over the methodological detail required for a research article. By ignoring the methodological detail of the research, the researchers are not providing the reflexivity that is required to reflect on such issues as the strengths and weaknesses of their chosen qualitative methodology (see Sparkes and Smith, 2014). It would be of benefit for future qualitative research to therefore include details of their methodology and the conduct of their work. This is because 'without a picture of what was done, it is difficult to make any judgement about whether this is likely to produce meaningful, trustworthy findings' (Garside, 2014, p.76).

Lastly, in regards to the conduct of a meta-synthesis, we would recommend that authors of future meta-syntheses keep a detailed reflexive journal of their decision making process throughout the five stages. A highly developed reflexive ability is required when conducting a meta-synthesis (Walsh and Downe, 2005) to enable the researchers to apply the same standards of quality to their work as they expect of the papers they are synthesising. One comment we were asked to reflect on was the ease of which we were able to compare and synthesis data sets between different qualitative methodologies. This task was not easy. However we aimed to preserve the meaning from the original text in the form of raw data as far as possible. As Walsh and Downe explain, this is because the 'goal is to increase understanding, leading to a greater explanatory effect, rather than to aggregate and merge findings' (p.209). We first compared and synthesised the data for barriers, benefits and facilitators of LTPA individually before it was apparent that some of the themes reoccurred across the data sets. We therefore presented the final themes as a collective of barriers, benefits and facilitators of LTPA. 


\section{Conclusion}

By synthesising existing qualitative knowledge, this paper provides a deep understanding of the factors that impact LTPA among people with SCI. Based on synthesised evidence, healthcare professionals need to appreciate the barriers, benefits and facilitators of LTPA in order to successfully promote a physically active lifestyle. An important finding was that many of the barriers to being physically active were reduced through LTPA participation. Additionally many of the benefits motivated people to continue being physically active. The multiple benefits from being physically active need to be communicated to the SCI community if they are to motivate people to change their exercise behaviour. Using stories from peers may be one way to effectively communicate these benefits to the wider SCI community. Equally, a more critical attitude by healthcare professionals to physical activity promotion is called for. The risks of participating in LTPA for recovery should not be overlooked. Future research should explore the long term impact of LTPA on and of well-being over time to further inform exercise promotions for people with SCI.

\section{Acknowledgements}

We would like to thank the editor, Prof Martin Hagger, and the anonymous reviewers for their detailed constructive feedback which enabled more conceptual clarity and enriched the discussion section.

\section{References}

Backus, D., \& Jones, M.L. (2013). Maximising research relevance to enhance knowledge translation. Archives of Physical Medicine and Rehabilitation, 94(1, Supplement), S1-S2.

Bowden, M. G., Hannold, E. M., Nair, P. M., Fuller, L. B., \& Behrman, A. L. (2008). Beyond gait speed: A case report of a multidimensional approach to locomotor rehabilitation outcomes in incomplete spinal cord injury. Journal of Neurologic Physical Therapy, 32(3), 129-138.

Bury, M. (1982). Chronic illness as biographical disruption. Sociology of Health and Illness, 4(2), 167-182.

Chen, Y., Cao, Y., Allen, V., \& Richards, S. (2011). Weight matters: Physical and psychosocial well-being of persons with spinal cord injury in relation to body mass index. Archives of Physical Medicine and Rehabilitation, 92, 391-398. 
Chun, S., \& Lee, Y. (2010). The role of leisure in the experience of posttraumatic growth for people with spinal cord injury. Journal of Leisure Research, 42(3), 393-415.

Cohen, S., Underwood, L., \& Gottlieb, B (eds.) (2000). Social support measurement and interventions: A guide for health and social scientists. New York: Oxford.

Cowan, R. E., Nash, M. S., \& Anderson, K. D. (2013). Exercise participation barrier prevalence and association with exercise participation status in individuals with spinal cord injury. Spinal Cord, 51, 27-32.

Dickson, A., Ward, R., O'Brien, G., Allan, D., \& O'Carroll, R. (2011). Difficulties adjusting to post-discharge life following a spinal cord injury: An interpretative phenomenological analysis. Psychology, Health and Medicine, 16(4), 463-474.

Fekete, C., \& Rauch, A. (2012). Correlates and determinants of physical activity in persons with spinal cord injury: A review using the international classification of functioning, disability and health as reference framework. Disability and Health Journal, 5(3), 140-150.

Frank, A. W. (2013). The wounded storyteller ( ${ }^{\text {nd }}$ ed.). London: University of Chicago Press.

Gainforth, H.L., Latimer-Cheung, A.E., Athanasopoulous, P., \& Martin-Ginis, K.A. (2013). Examining the effectiveness of a knowledge mobilization initiative for disseminating the physical activity guidelines for people with spinal cord injury. Disability and Health Journal, 6, 260-265.

Garside, R. (2014). Should we appraise the quality of qualitative research reports for systematic reviews, and if so, how? Innovation: The European Journal of Social Science Research, 27(1), 67-79.

Hagger, M. S. (2013). What reviewers want: How to make your article more appealing to peer reviewers. Health Psychology Review, 7, S1-S7.

Hammell, K.W. (2007). Quality of life after spinal cord injury: A meta-synthesis of qualitative findings. Spinal Cord, 45(2), 124-139.

Hannold, E. M., Young, M. E., Rittman, M. R., Bowden, M. G., \& Behrman, A. L. (2006). Locomotor training: Experiencing the changing body. Journal of Rehabilitation Research and Development, 43(7), 905-916.

Hitzig, S. L., Tonack, M., Campbell, K., McGillivray, C. F., Boschen, K., Richards, K., \& Craven, C. B. (2008). Secondary health complications in an aging Canadian spinal cord injury sample. American Journal of Physical Medicine and Rehabilitation, 87(7), 545-555. 


\section{RUNNING HEAD: PHYSICAL ACTIVITY AND SPINAL CORD INJURY}

Jefferies, P., Gallagher, P. \& Dunne, S. (2012). The Paralympic athlete: a systematic review of the psychosocial literature. Prosthetics and Orthotics International, 36(3), 278-89

Kehn, M., \& Kroll, T. (2009). Staying physically active after spinal cord injury: A qualitative exploration of barriers and facilitators to exercise participation. BMC Public Health, 9, 168178.

Kehn, M., \& Kroll, T. (2009). Staying physically active after spinal cord injury: A qualitative exploration of barriers and facilitators to exercise participation. BMC Public Health, 9, 168178.

Keyes, C. L., Shmotkin, D., \& Ryff, C. D. (2002). Optimizing well-being: The empirical encounter of two traditions. Journal of Personality and Social Psychology, 82(6), 10071022.

Keyes, C.L.M. (1998). Social well-being. Social Psychological Quarterly, 61, 121-140.

Kleiber, D.A., \& Hutchinson, S.L. (1999). Heroic masculinity in the recovery from spinal cord injury. In: A. Sparkes \& M. Silvennoinen (eds.), Talking bodies: Men's narratives of the body and sport (pp.135-155). Jyvaskyla: SoPhi University of Jyvaskyla.

Krause, K. S., \& Saunders, L. L. (2011). Health, secondary conditions, and life expectancy after spinal cord injury. Archives of Physical Medicine and Rehabilitation, 92(11), 1770-1775.

Larsson, A.T., \& Grassman, E.J. (2012) Bodily changes among people living with physical impairments and chronic illnesses: biographical disruption or normal illness? Sociology of Health \& Illness, 34(8), 1156-1169.

Letts, L., Martin Ginis, K. A., Faulkner, G., Colquhoun, H., Levac, D., \& Gorczynski, P. (2011). Preferred methods and messengers for delivering physical activity information to people with spinal cord injury: A focus group study. Rehabilitation Psychology, 56(2), 128-137.

Letts, L., Martin Ginis, K. A., Faulkner, G., Colquhoun, H., Levac, D., \& Gorczynski, P. (2011). Preferred methods and messengers for delivering physical activity information to people with spinal cord injury: A focus group study. Rehabilitation Psychology, 56(2), 128-137.

Levins, S. M., Redenbach, D. M., \& Dyck, I. (2004). Individual and societal influences on participation in physical activity following spinal cord injury: A qualitative study. Physical Therapy, 84(6), 496-509. 
Levins, S. M., Redenbach, D. M., \& Dyck, I. (2004). Individual and societal influences on participation in physical activity following spinal cord injury: A qualitative study. Physical Therapy, 84(6), 496-509.

Löfgren, M., \& Norrbrink, C. (2012). 'But I know what works’ patients' experience of spinal cord injury neuropathic pain management. Disability and Rehabilitation, 34(25), 2139-2147.

Manns, P. J., \& Chad, K. E. (2001). Components of quality of life for persons with a quadriplegic and paraplegic spinal cord injury. Qualitative Health Research, 11(6), 795-811.

Martin Ginis, K. A., Arbour-Nicitopoulos, K. P., Latimer, A. E., Buchholz, A. C., Bray, S. R., Craven, B. C., Hayes, K.C., Hicks, A.L., McColl, M.A., Potter, P.J., Smith, K., \& Wolfe, D. L. (2010). Leisure time physical activity in a population-based sample of people with spinal cord injury part II: Activity types, intensities, and durations. Archives of Physical Medicine and Rehabilitation, 91(5), 729-733.

Martin Ginis, K. A., Jörgensen, S., \& Stapleton, J. (2012). Exercise and sport for persons with spinal cord injury. $P M \& R, 4(11)$, 894-900.

Martin, K. A., Latimer, A. E., Francoeur, C., Hanley, H., Watson, K., Hicks, A. L., \& McCartney, N. (2002). Sustaining exercise motivation and participation among people with spinal cord injuries - lessons learned from a 9-month intervention. Palaestra, 18(1), 38-40.

Mazanderani, F., Locock, L., \& Powell, J. (2013). Biographical value: towards a conceptualisation of the commodification of illness narratives in contemporary healthcare. Sociology of Health \& Illness, 35(6), 891-905.

Mulligan, H. F., Hale, L. A., Whitehead, L., \& Baxter, G. D. (2012). Barriers to physical activity for people with long-term neurological conditions: A review study. Adapted Physical Activity Quarterly, 29(3), 243-265.

Nunnerley, J., Hay-Smith, E., \& Dean, S. (2013). Leaving a spinal unit and returning to the wider community: An interpretative phenomenological analysis. Disability \& Rehabilitation, 35(14), 1164-1173.

O'Brien, A., Renwick, R., \& Yoshida, K. (2008). Leisure participation for individuals living with acquired spinal cord injury. International Journal of Rehabilitation Research, 31(3), 225230. 


\section{RUNNING HEAD: PHYSICAL ACTIVITY AND SPINAL CORD INJURY}

O'Connell, R., \& Downe, S. (2009). A metasynthesis of midwives' experience of hospital practice in publicly funded settings: Compliance, resistance and authenticity. Health: 13(6), 589-609.

Pentland, W., Walker, J., Minnes, P., Tremblay, M., Brouwer, B., \& Gould, M. (2002). Women with spinal cord injury and the impact of aging. Spinal Cord, 40(8), 374-387.

Price, P., Stephenson, S., Krantz, L., \& Ward, K. (2011). Beyond my front door: The occupational and social participation of adults with spinal cord injury. OTJR Occupation, Participation and Health, 31(2), 81-88.

Ryan, R. M., \& Deci, E. L. (2001). ON HAPPINESS AND HUMAN POTENTIALS: A review of research on hedonic and eudaimonic well-being. Annual Review of Psychology, 52(1), 141-166.

Saebu, M. (2010). Physical disability and physical activity: A review of the literature on correlates and associations. European Journal of Adapted Physical Activity, 3(2), 37-55.

Semerjian, T. Z., Montague, S. M., Dominguez, J. F., Davidian, A. M., \& De Leon, R. D. (2005). Enhancement of quality of life and body satisfaction through the use of adapted exercise devices for individuals with spinal cord injuries. Topics in Spinal Cord Injury Rehabilitation, 11(2), 95-108.

Smith, B. (2013). Disability, sport and men's narratives of health: A qualitative study. Health Psychology, 32(1), 110-119.

Smith, B. (2013). Disability, sport and men's narratives of health: A qualitative study. Health Psychology, 32(1), 110-119.

Smith, B., \& Perrier, M-J. (in-press). Disability, sport and impaired bodies: A critical approach. In. R. Schinke \& K.R. McGannon. The Psychology of Sub-Culture in Sport and Physical Activity: A Critical Approach. London: Psychology Press.

Smith, B., \& Sparkes, A.C. (2005). Men, sport, spinal cord injury and narratives of hope. Social Science and Medicine, 61, 1095-1105.

Sparkes, A. C., \& Smith, B. (2009). Judging the quality of qualitative inquiry: Criteriology and relativism in action. Psychology of Sport and Exercise, 10(5), 491-497.

Sparkes, A.C. \& Smith, B. (2014). Qualitative Research Methods in Sport, Exercise \& Health. From process to product. London: Routledge. 
RUNNING HEAD: PHYSICAL ACTIVITY AND SPINAL CORD INJURY

Stephens, C., Neil, R., \& Smith, P. (2012). The perceived benefits and barriers of sport in spinal cord injured individuals: A qualitative study. Disability and Rehabilitation, 34(24), 20612070.

van de Ven, L., Post, M., de Witte, L., \& van den Heuvel, W. (2008). Strategies for autonomy used by people with cervical spinal cord injury: A qualitative study. Disability \& Rehabilitation, 30(4), 249-260.

Vissers, M., van den Berg-Emons, R., Sluis, T., Bergen, M., Stam, H., \& Bussmann, H. (2008). Barriers to and facilitators of everyday physical activity in persons with a spinal cord injury after discharge from the rehabilitation centre. Journal of Rehabilitation Medicine, 40, 461467.

Wahman, K., Biguet, G., \& Levi, R. (2006). What promotes physical activity after spinal cord injury? an interview study from a patient perspective. Disability and Rehabilitation: An International, Multidisciplinary Journal, 28(8), 481-488.

Walsh, D., \& Downe, S. (2005). Meta-synthesis method for qualitative research: A literature review. Journal of Advanced Nursing, 50(2), 204-211.

Weed, M. (2008). A potential method for the interpretive synthesis of qualitative research: Issues in the development of 'Meta-Interpretation'. International Journal of Social Research Methodology, 11(1), 13-28.

Williams, S. (2000). Chronic illness as biographical disruption or biographical disruption as chronic illness? reflections on a core concept. Sociology of Health \& Illness, 22(1), 40-67. 